\title{
Effects of yield point and plastic anisotropy on results of elastic-plastic finite element analysis of tension leveling
}

Changxiang Fan ( $\sim$ fan@race.t.u-tokyo.ac.jp )

The University of Tokyo: Tokyo Daigaku https://orcid.org/0000-0002-5939-6754

Honghao Wang

The University of Tokyo: Tokyo Daigaku

\section{Ye Zhang}

The University of Tokyo: Tokyo Daigaku

\section{Dexin Chen}

Jinan University

Jing Guo

Guangdong University of Technology

Jun Yanagimoto

The University of Tokyo

\section{Original Article}

Keywords: Tension leveling, Constitutive model, Finite element analysis, Anisotropy, Yield point

Posted Date: October 28th, 2021

DOI: https://doi.org/10.21203/rs.3.rs-1017155/v1

License: (9) (i) This work is licensed under a Creative Commons Attribution 4.0 International License.

Read Full License 


\section{Title page}

\section{Effects of yield point and plastic anisotropy on results of elastic-plastic finite element analysis of tension leveling}

Honghao Wang, born in 1993, is currently a $\mathrm{PhD}$ candidate at the University of Tokyo, Japan. He received his master degree from Graduate School of Engineering at the University of Tokyo, Japan, in 2018. His research interest includes the physical and numerical simulation of sheet metal forming.

E-mail: honghao.wang@cem.t.u-tokyo.ac.jp

Ye Zhang, born in 1993, is currently a PhD candidate at the University of Tokyo, Japan. He received his master degree from Graduate School of Engineering at the University of Tokyo, Japan, in 2018. His research interest includes the finite element analysis and composite materials.

E-mail: zhang-ye@cfrtp.t.u-tokyo.ac.jp

Changxiang Fan, born in 1990, is currently a project researcher of Research into Artifacts, Center for Engineering (RACE), School of Engineering, the University of Tokyo, Japan. He received Ph.D. degree in Precision Engineering in 2020 from The University of Tokyo, Tokyo, Japan. His research interests include mechanical design and robotics.

Tel: +86-13416158651; E-mail: fan@ race.t.u-tokyo.ac.jp

Dexin Chen, born in 1991, is currently associate professor at Institute of Advanced Wear \& Corrosion Resistant and Functional Materials, Jinan University, China. He received his PhD degree from South China University of Technology, China, in 2018. His research interests include surface modification and functional coatings.

Email: dxchen@jnu.edu.cn

Jing Guo is currently an associate professor affiliated with Guangdong University of Technology, China. He received his Ph.D. degree from LIRMM, CNRS-University of Montpelier, France in 2016. His current research interests include robotic control and learning, haptic bilateral teleoperation, and surgical robotics. He has served as guest editor for IEEE RA-L, Frontiers in Robotics \&AI, etc.

E-mail: jing.guo@gdut.edu.cn

Jun Yanagimoto, born in 1961, is currently a professor at the University of Tokyo, Japan. He received his Ph.D. degree from Graduate School of Engineering at the University of Tokyo, Japan, in 1989. His research interest includes fundamental investigation in manufacturing formable high-strength steel strips with bimodal microstructure, physical and numerical simulations on metal, and decoding material genome for the analysis of microstructure evolution in hot forming.

E-mail: jun.52074.yanagimoto@cem.t.u-tokyo.ac.jp

\section{Corresponding author: Changxiang Fan E-mail: fan@race.t.u-tokyo.ac.jp}




\title{
Effects of yield point and plastic anisotropy on results of elastic-plastic finite element analysis of tension leveling
}

\author{
Honghao Wang ${ }^{1} \cdot$ Ye Zhang $^{1} \cdot$ Changxiang Fan $^{2} \cdot$ Dexin Chen $^{3} \cdot \mathrm{Jing}_{\text {Guo }}{ }^{4} \cdot \mathrm{Jun} \mathrm{Yanagimoto}^{1}$
}

Received June xx, 201x; revised February xx, 201x; accepted March xx, 201x

(c) Chinese Mechanical Engineering Society and Springer-Verlag Berlin Heidelberg 2017

\begin{abstract}
Tension leveling is an important industrial process to eliminate the flatness defects and residual stresses of metal strips to provide high-quality sheet metals for subsequent sheet metal forming. The finite element (FE) method can be applied to elucidate the effects of process parameters on the quality of sheets after tension leveling for various materials. In our previous investigation, an accurate FE model considering the anisotropy and cyclic plasticity of materials has been established for the elastic-plastic FE analysis of tension leveling. In this study, we further studied the effects of the yield point and plastic anisotropy on tension leveling using the FE model established in our previous investigation. Aiming at improving the accuracy of simulation, a modified constitutive model was developed to describe the anisotropic hardening of materials under cyclic loading. The modified constitutive model was implemented into Abaqus/Standard as a user-defined material (UMAT) subroutine to simulate the development of the anisotropy in materials during tension leveling. The modified model was also applied to the FE analysis of sheet metal forming processes to demonstrate its simulation capability and accuracy.
\end{abstract}

Keywords: Tension leveling - Constitutive model • Finite element analysis $\bullet$ Anisotropy $\bullet$ Yield point

\section{Changxiang Fan}

fan@ race.t.u-tokyo.ac.jp

1 Graduate School of Engineering, The University of Tokyo, Hongo 7-3-1, Bunkyo, Tokyo, Japan

2 RACE (Research into Artifacts, Center for Engineering), School of Engineering, The University of Tokyo, Hongo 7-3-1, Bunkyo, Tokyo, Japan

3 Institute of Advanced Wear \& Corrosion Resistant and Functional Materials, Jinan University, 601 Huangpu Avenue West, Guangzhou 510632, China

4 School of Automation, Guangdong University of Technology, Guangzhou 510006, China

\section{Introduction}

Tension leveling is widely applied in industry to eliminate the flatness defects and residual stresses of metal strips. The finite element (FE) method can be applied to elucidate the effects of process parameters on the quality of sheets after tension leveling for various materials. Recently, with aims to clarify the factors affecting this process and achieve simulations of tension leveling with high accuracy, many researchers conducted related studies. Zhao et al. [1] conducted the FE analysis of tension leveling to determine the relationship between the intermesh of the leveler rolls and the working curvatures of leveled strips under a specific leveling arrangement. Zhang et al. [2] conducted tension leveling tests to investigate the effects of tension leveling elongation and intermesh of leveler rolls on tension leveling. They found that both factors can influence the microstructure and mechanical properties of leveled steel strips, indicating the possibility of improving steel strip properties by adjusting the elongation and intermesh during tension leveling. Garcia et al. [3] applied different work hardening models to the FE analysis of tension leveling and concluded that the introduced hardening rule is an important input in the FE analysis of tension leveling since it influences simulation results. Although previous investigations have clarified some factors affecting tension leveling such as the arrangement and intermesh of leveler rolls and the work hardening properties of materials, further investigations must be conducted 1) to reveal much more factors that affect tension leveling to provide a deeper insight into this process, 2) to improve the accuracy of tension leveling simulation, and 3) to realize consistency analysis of tension leveling and subsequent sheet metal forming considering the tension leveling history.

In our previous investigation [4], an FE model 
considering the anisotropy and cyclic plasticity of materials using the Hill48 yield criterion with the non-associated flow rule and the mixed hardening rule has been established for the elastic-plastic FE analysis of tension leveling. In this study, we further studied the effects of the yield point and plastic anisotropy on tension leveling using the FE model established in our previous investigation. On the basis of the effects of the plastic anisotropy on the results of the FE analysis of tension leveling, the constitutive model in our previous investigation [4] is modified to simulate the development of the anisotropy in materials during tension leveling.

\section{FE modeling of tension leveling}

The arrangement of leveler rolls used for tension leveling [5] in this study is shown in Figure 1. The FE model of tension leveling is based on this arrangement in Abaqus/Standard, where leveler rolls are modeled as analytical rigid bodies and leveled strips are discretized as second-order brick elements. The dimensions of a leveled strip were $1300 \mathrm{~mm}$ length $(x) \times 200 \mathrm{~mm}$ width $(y) \times 0.5 \mathrm{~mm}$ thickness $(z)$, and the corresponding mesh size was set to $5 \mathrm{~mm}(x) \times 10 \mathrm{~mm}(y)$ with four elements in the thickness direction. For the material properties of the leveled strips, the user-defined material (UMAT) subroutine of Abaqus/Standard was used to implement the material properties (e.g., the Bauschinger effect, plastic anisotropy, and yield point) investigated in this study with the fully implicit backward Euler return mapping algorithm [4]. The static implicit step was applied to simulate this process. For all simulated cases, the Young's modulus and Poisson's ratio of the leveled strips were set to $210 \mathrm{GPa}$ and 0.3 , respectively. The friction coefficient between the leveler roll and the leveled strip was set to 0.15 . For each simulated case, the tension was set to $40 \mathrm{MPa}$ and the intermesh of the leveler rolls was set to a constant value.

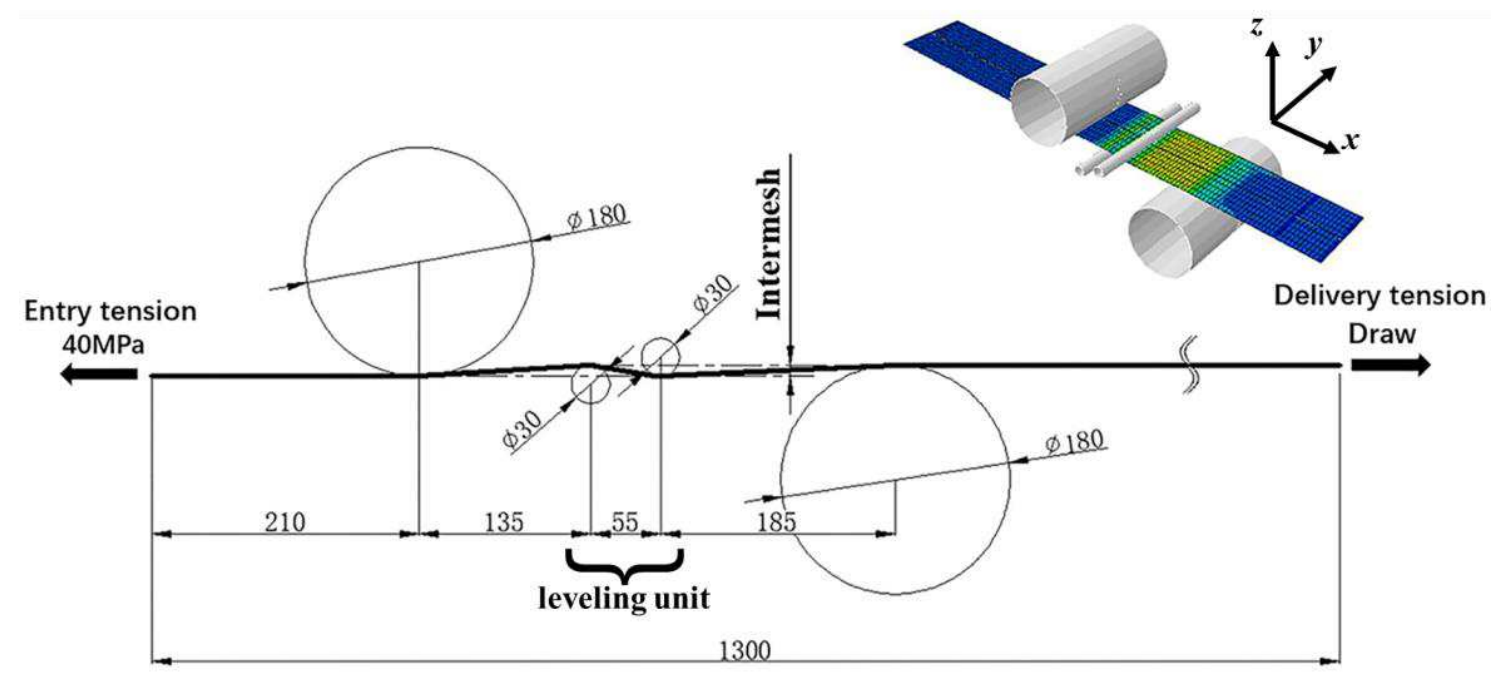

Figure 1 Arrangement of leveler rolls and FE model for tension leveling.

\section{Effects of yield point on finite element analysis results of tension leveling}

The yield point phenomenon is a common property of metal materials such as mild steels [6], aluminum alloys [7] and titanium alloys [8]. Regarding the true stress-strain behavior, it is characterized by a yield drop and the subsequent strain hardening [6], as shown in Figure 2. The effects of the yield point on processes involving cyclic loading have been investigated by many researchers. Žerovnik et al. [9] conducted uniaxial cyclic loading tests to study the effects of the yield point on the stress-strain responses and strain fields of cyclically loaded specimens. They also proposed a constitutive model for the yield point phenomenon in cyclic plasticity and applied it to the simulation of a cyclically loaded console beam to reveal the effects of the yield point phenomenon on the accumulated plastic strain after several loading cycles [10]. Kim et al. [11] conducted roller leveling to study the reduction of yield point during leveling. Materials are also subjected to cyclic loading during tension leveling and the effects of the yield point on this process have not been investigated; thus, we conducted FE analysis using the constitutive model applied in our previous investigation reported in Ref. [4] (the Hill48 yield criterion with the non-associated flow rule and the mixed hardening rule, briefly summarized in Appendix I) to study the effects of the yield point phenomenon on tension leveling. 


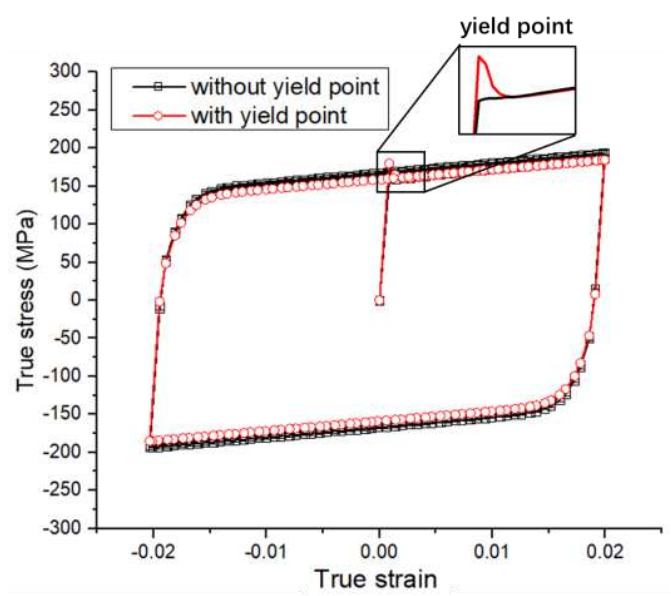

Figure 2 Stress-strain responses during cyclic loading of materials with and without yield point.

In this section, two types of virtual material with and without a yield point are adopted to study the effects of the yield point phenomenon on tension leveling. The virtual materials are both considered as isotropic using the constitutive model in Ref. [4] $\left(\mathrm{H}=\mathrm{G}=\mathrm{F}=\mathrm{H}^{*}=\mathrm{G}^{*}=\mathrm{F}^{*}=1\right.$, $\mathrm{L}=\mathrm{M}=\mathrm{N}=\mathrm{L}^{*}=\mathrm{M}^{*}=\mathrm{N}^{*}=3$ ) and the stress - strain responses during cyclic loading are shown in Figure 2. The only difference between these two materials is in the presence or absence of a yield point. The corresponding work hardening parameters of the constitutive model in Ref. [4] are shown in Table 1. The FE model mentioned in section 2 was adopted to conduct the FE analysis of tension leveling. The intermeshes were set to $2.5 \mathrm{~mm}$ and $5.0 \mathrm{~mm}$ for these two materials in the FE model. After tension leveling, the residual curvatures in the $\mathrm{x}$ direction (regarded as curl) of the leveled strip after springback and the total elongations (the sum of the elastic and plastic elongations) in the $\mathrm{x}$ direction of the leveled strip at the exit of the leveling unit were measured in each simulated case and the results are shown in Table 2 (all results are the averages of the measured residual curvatures and total elongations at the center and edge of the leveled strip). The difference between these two materials indicates that the yield point phenomenon has an effect on tension leveling. To evaluate the effect in detail, the total elongation of each layer, which is calculated as the average of the center and edge parts of the leveled strip when the leveled strip passes through the leveling unit with an intermesh of $2.5 \mathrm{~mm}$, was measured numerically for the two materials. The elongation history results of the two materials are compared in Figure 3. It is shown that not only the yield point leads to a smaller elongation at the exit of the leveling unit than in the simulated case without the yield point (as shown in Table 2), but also the elongation histories in the leveling unit for materials with and without a yield point are slightly different (especially for the central layer). Taken together, it can be concluded from the FE analysis results that the yield point has influence on the elongation of the leveled strip during tension leveling.

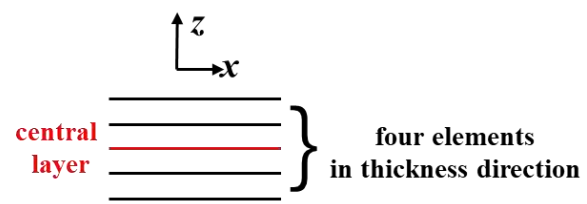

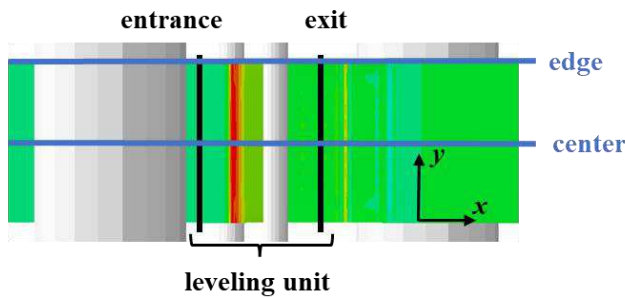

$\longrightarrow$ layer 1 with y.p. $\rightarrow-$ - layer 1 without y.p. $\longrightarrow$ layer 2 with y.p $-\rightarrow-$ layer 2 without y.p. $\longrightarrow$ central layer with y.p - - central layer without y.p. $\longrightarrow$ layer 4 with y.p. $\ldots$ layer 4 without y.p. $\longrightarrow$ layer 5 with y.p. $\rightarrow-$ layer 5 without y.p.

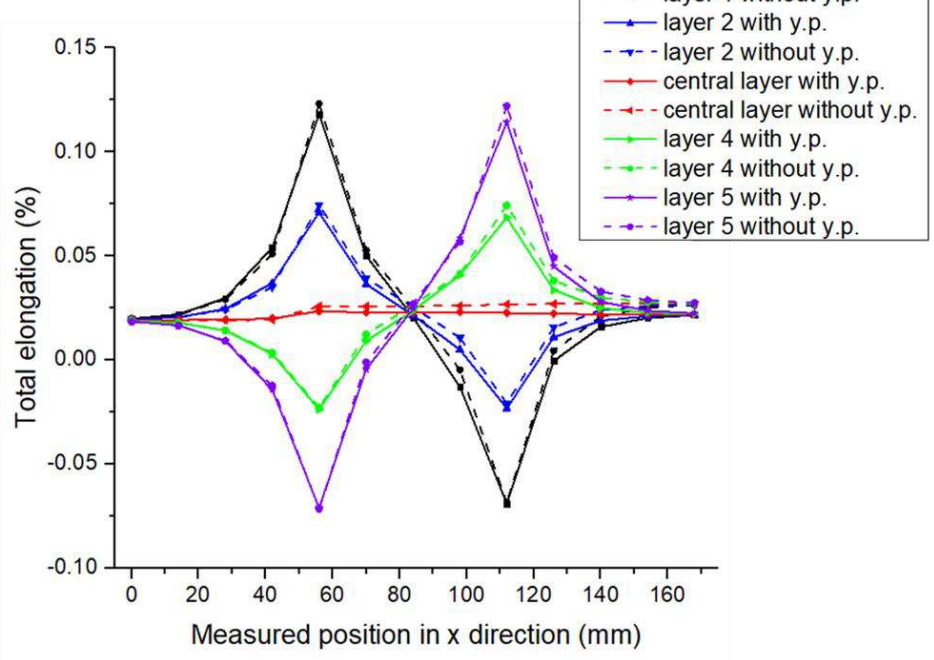

Figure 3 Total elongations in leveling unit with intermesh of $2.5 \mathrm{~mm}$ for materials with and without yield point. 
Table 1 Parameters of work hardening rule with and without yield point

\begin{tabular}{ccccccc}
\hline & $\sigma^{0}$ & $Q$ & $b$ & $C_{1}$ & $C_{2}$ & $\gamma$ \\
\hline with yield point & 200 & -40 & 3000 & 50000 & 1300 & 900 \\
without yield point & 160 & 10 & 15 & 50000 & 1300 & 900 \\
\hline
\end{tabular}

Table 2 FE analysis results with and without yield point

\begin{tabular}{|c|c|c|c|c|}
\hline \multirow{2}{*}{$\begin{array}{l}\text { Intermesh } \\
{[\mathrm{mm}]}\end{array}$} & \multicolumn{2}{|c|}{ Residual curvature in $x$ direction $\left[\mathrm{m}^{-1}\right]$} & \multicolumn{2}{|c|}{ Total elongation at exit of leveling unit [\%] } \\
\hline & $\begin{array}{c}\text { with } \\
\text { yield point }\end{array}$ & $\begin{array}{l}\text { without } \\
\text { yield point }\end{array}$ & $\begin{array}{c}\text { with } \\
\text { yield point }\end{array}$ & $\begin{array}{l}\text { without } \\
\text { yield point }\end{array}$ \\
\hline 2.5 & 0.323 & 0.487 & 0.0219 & 0.0265 \\
\hline 5.0 & 0.873 & 1.006 & 0.0556 & 0.0615 \\
\hline
\end{tabular}

Table 3 Constitutive parameters with different anisotropic parameters

\begin{tabular}{ccccccc}
\hline \multirow{2}{*}{$\begin{array}{c}\text { Hill48 with } \\
\text { associated flow rule }\end{array}$} & \multicolumn{2}{c}{$H$} & $G$ & $F$ & $L, M, N$ \\
& \multicolumn{2}{c}{$0.25 / 0.50 /$} & & $0.25 / 0.50 /$ & $0.25 / 0.50 /$ & $1.50 / 2.00 /$ \\
& $0.75 / 1.00$ & & $0.75 / 1.00$ & $0.75 / 1.00$ & $2.50 / 3.00$ \\
\hline \multirow{2}{*}{ mixed hardening rule } & $\sigma^{0}$ & $Q$ & $b$ & $C_{1}$ & $C_{2}$ & $\gamma$ \\
\cline { 2 - 7 } & 158.9 & 50.4 & 65.4 & 54468.9 & 889.3 & 1359.7 \\
\hline
\end{tabular}

\section{Investigation of plastic anisotropy of materials during tension leveling}

\subsection{Effects of plastic anisotropy on finite element analysis results of tension leveling}

Plastic anisotropy is a significant factor affecting the forming of sheet metals [12]. Recently, several studies have been conducted to determine the effects of plastic anisotropy on sheet metal forming. Wu et al. [13] combined the yld91 model with the Hill48 model under the non-associated flow rule with the anisotropic hardening to elucidate the influence of the evolution of plastic anisotropy during the hole expansion of JSH590R sheets. Kim et al. [14] developed several constitutive models based on the non-associated flow rule using the Hill48, Yld2000-2d and Yoshida polynomial functions to simulate hole expansion tests. They found that the anisotropy of the plastic potential function plays an important role in the thinning behavior prediction. Hu et al. [15] coupled the poly4 and Hosford yield functions under the associated flow rule to evaluate the anisotropic yielding behavior of aluminum alloy sheets during cup drawing to achieve an accurate FE simulation. To clarify the effects of plastic anisotropy on tension leveling, we conducted FE analysis using the Hill48 yield criterion with the associated flow rule and the mixed hardening rule, and the tension leveling results of virtual materials with different anisotropies were evaluated in our previous study [16]. The corresponding constitutive model and parameters are shown in Table 3.
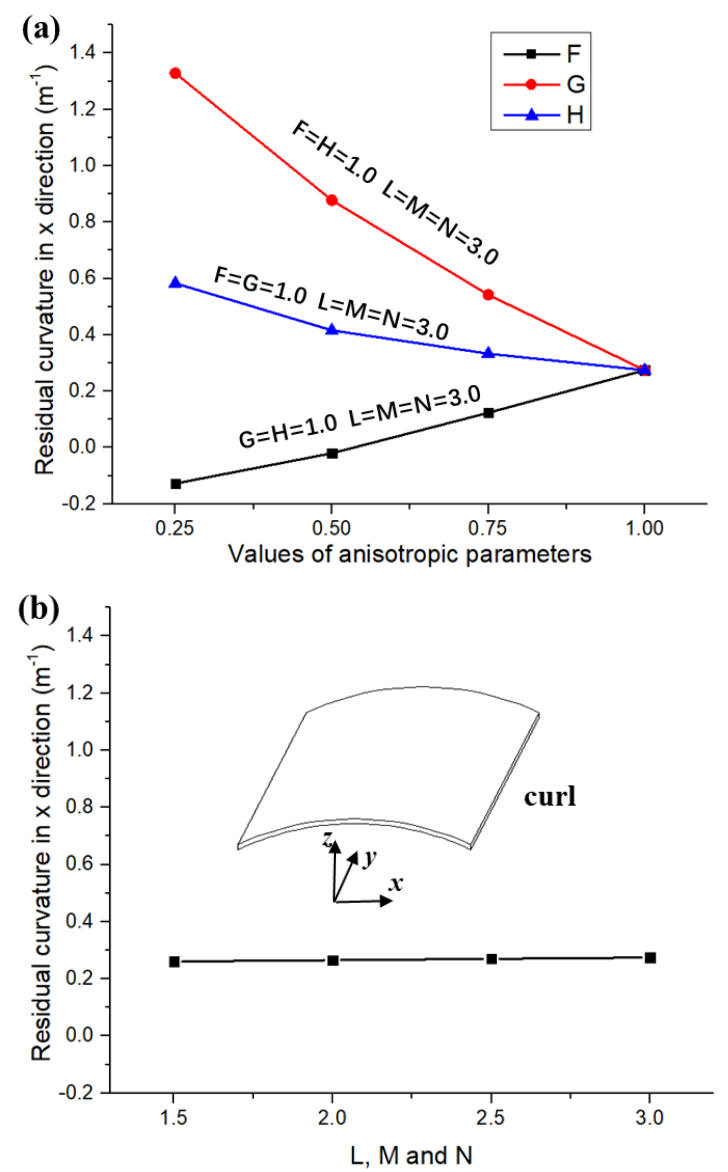

Figure 4 Simulation results of curl with different values of anisotropic parameters (a) F, G and H, and (b) L, M and N. 

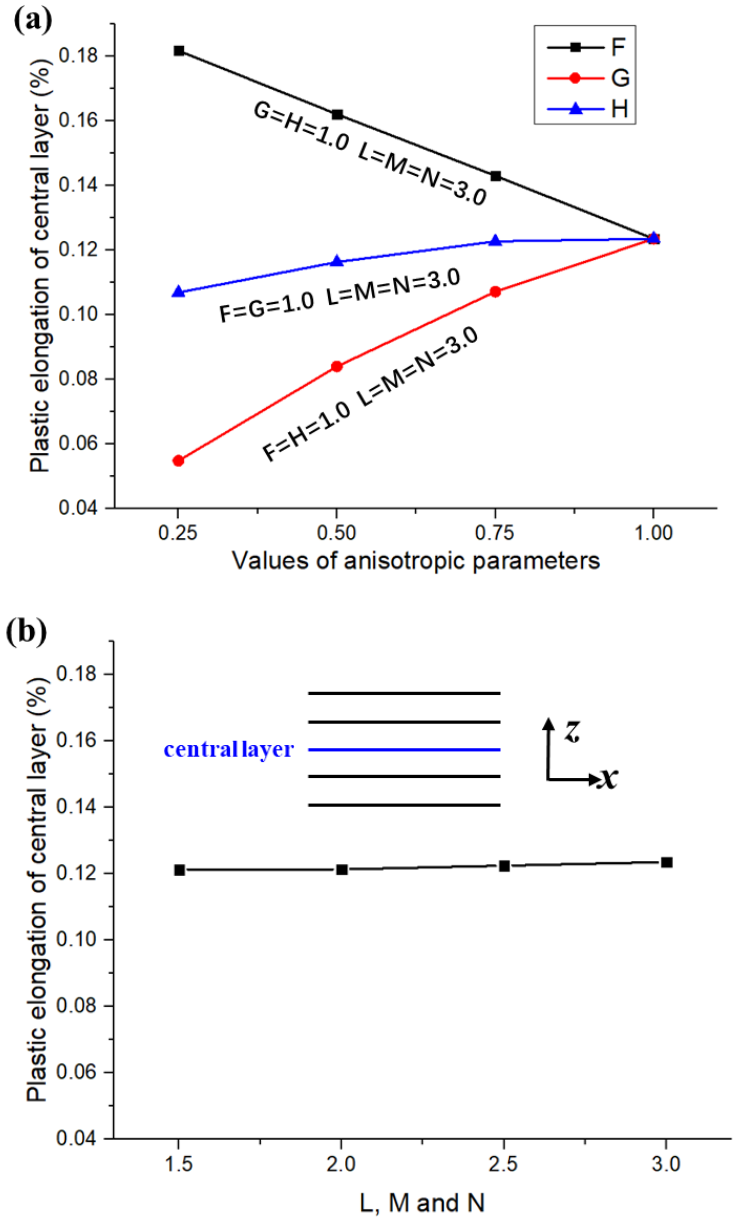

Figure 5 Simulation results of plastic elongation of central layer with different values of anisotropic parameters (a) F, G and $\mathrm{H}$, and (b) L, M and $\mathrm{N}$.

The FE analysis of tension leveling using the FE model mentioned in section 2 was conducted for those materials with different anisotropic parameters to further study the effects of plastic anisotropy on the FE analysis results of tension leveling. In all simulated cases, the intermesh was set to $10 \mathrm{~mm}$.

For the residual curvatures in the $x$ direction after tension leveling (regarded as curl, shown in Figure 4), when the anisotropic parameters $\mathrm{F}, \mathrm{G}$ and $\mathrm{H}$ change, the values of curl also change. For L, M and N, the effects are not significant since those anisotropic parameters are related to shear stresses. It is concluded that plastic anisotropy affects the strain and stress distributions during the FE analysis of tension leveling, especially for the central layer [16]. Figure 5 shows the plastic elongation in the $x$ direction of the central layer after the tension leveling of the strips with different anisotropic parameters, indicating that the different anisotropic parameters F, G
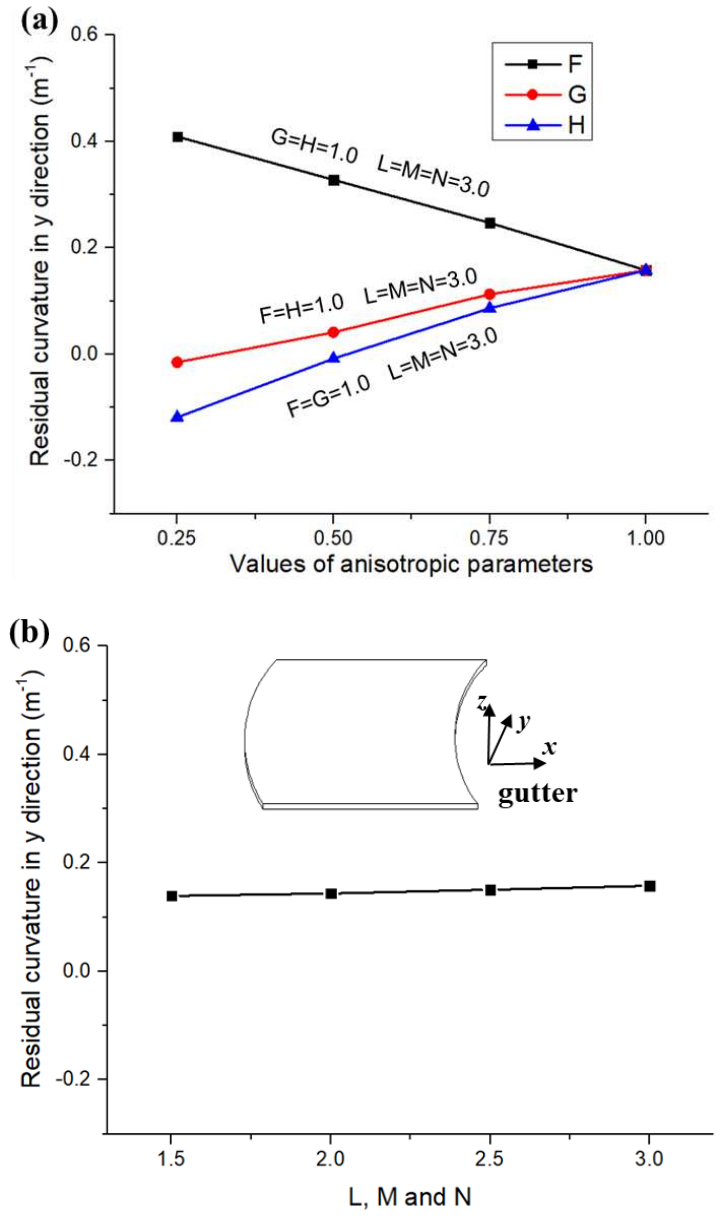

Figure 6 Simulation results of gutter with different values of anisotropic parameters

(a) $F, G$ and $H$, and (b) $L, M$ and $N$.

and $\mathrm{H}$ lead to different elongations of the leveled strips, resulting in different curl values. The effects of plastic anisotropy on the residual curvatures in the $y$ direction (regarded as gutter, shown in Figure 6) after tension leveling are also evaluated in this investigation. Similar to the results of curl values, when $\mathrm{F}, \mathrm{G}$ and $\mathrm{H}$ change, the values of the gutter also change, but the trend of the values of the gutter is opposite to that of the curl values when F, G and $\mathrm{H}$ increase. For L, M and N, no significant effects are observed. Plastic anisotropy can both affect the curl and gutter of the leveled strips after tension leveling; thus, it is an important factor affecting tension leveling.

\subsection{Application of modified anisotropic constitutive model to finite element analysis of tension leveling}

In our previous investigation [4], the Hill48 with the non-associated flow rule and the mixed hardening rule was adopted as the constitutive model to conduct the FE analysis of tension leveling (details in Appendix I). 
However, the Hill48 yield criterion applied in that constitutive model is with constant anisotropic parameters identified from the initial yielding surface (Eqs. (A6-A7)). Thus, the constitutive model in Ref.[4] can only capture the anisotropy of initial yield stresses of materials. For steel sheets, besides the anisotropy of initial yield stresses, the evolution of the subsequent hardening also shows anisotropic behavior [17]. It is concluded in section 4.1 that the anisotropic parameters affect the FE analysis results of tension leveling since the $\mathrm{FE}$ results vary with the anisotropic parameters. This finding implies the necessity of applying an anisotropic yield function with variable anisotropic parameters in a constitutive model to capture the anisotropic evolution of the work hardening behavior of materials during the $\mathrm{FE}$ analysis of tension leveling. Thus, the constitutive model applied in Ref. [4] was modified considering the anisotropic hardening under cyclic loading in the FE analysis of tension leveling. The details of the modified constitutive model are shown as follows.

\section{Work hardening rule:}

$$
\begin{aligned}
& f(\boldsymbol{\eta})=\eta_{0}\left(\bar{\varepsilon}^{p}\right) \\
& \boldsymbol{\eta}=\left[\begin{array}{c}
\eta_{x x} \\
\eta_{y y} \\
\eta_{z z} \\
\eta_{x y} \\
\eta_{x z} \\
\eta_{y z}
\end{array}\right]=\boldsymbol{\sigma}-\boldsymbol{\alpha}=\left[\begin{array}{c}
\sigma_{x x} \\
\sigma_{y y} \\
\sigma_{z z} \\
\sigma_{x y} \\
\sigma_{x z} \\
\sigma_{y z}
\end{array}\right]-\left[\begin{array}{c}
\alpha_{x x} \\
\alpha_{y y} \\
\alpha_{z z} \\
\alpha_{x y} \\
\alpha_{x z} \\
\alpha_{y z}
\end{array}\right] \\
& \boldsymbol{\alpha}=\left[\begin{array}{l}
\alpha_{x x} \\
\alpha_{y y} \\
\alpha_{z z} \\
\alpha_{x y} \\
\alpha_{x z} \\
\alpha_{y z}
\end{array}\right]=\boldsymbol{\alpha}_{\mathbf{1}}+\boldsymbol{\alpha}_{\mathbf{2}}=\left[\begin{array}{l}
\alpha_{1, x x} \\
\alpha_{1, y y} \\
\alpha_{1, z z} \\
\alpha_{1, x y} \\
\alpha_{1, x z} \\
\alpha_{1, y z}
\end{array}\right]+\left[\begin{array}{l}
\alpha_{2, x x} \\
\alpha_{2, y y} \\
\alpha_{2, z z} \\
\alpha_{2, x y} \\
\alpha_{2, x z} \\
\alpha_{2, y z}
\end{array}\right] \\
& d \alpha_{1, m}=\left(\frac{\eta_{m} C_{1, m}}{g(\eta)}-\gamma_{m} \alpha_{1, m}\right) d \bar{\varepsilon}^{p}, m=x x, y y, z z, x y, x z, y z \\
& d \alpha_{2, m}=\frac{\eta_{m} C_{2, m}}{g(\eta)} d \bar{\varepsilon}^{p}, \quad m=x x, y y, z z, x y, x z, y z \\
& \eta_{n}\left(\bar{\varepsilon}^{p}\right)=\eta_{n}^{0}+Q_{n}\left(1-e^{-b_{n} \bar{\varepsilon}^{p}}\right)-\frac{C_{1, n}}{\gamma_{n}}\left(1-e^{-\gamma_{n} \bar{\varepsilon}^{p}}\right), n=0,45,90, N D \\
& C_{1, x x}=C_{1,0} \\
& C_{1, y y}=C_{1,90} \\
& C_{1, Z Z}=C_{1, N D} \\
& C_{1, x y}=C_{1, x z}=C_{1, y z}=\frac{4 C_{1,45}-C_{1, N D}}{3} \\
& C_{2, x x}=C_{2,0} \\
& C_{2, y y}=C_{2,90} \\
& C_{2, Z Z}=C_{2, N D} \\
& C_{2, x y}=C_{2, x z}=C_{2, y z}=\frac{4 C_{2,45}-C_{2, N D}}{3} \\
& \gamma_{x x}=\gamma_{0} \\
& \gamma_{y y}=\gamma_{90} \\
& \gamma_{z Z}=\gamma_{N D} \\
& \gamma_{x y}=\gamma_{x z}=\gamma_{y z}=\frac{4 \gamma_{45}-\gamma_{N D}}{3}
\end{aligned}
$$


Here, $f(\boldsymbol{\eta})$ is the yield function. $\boldsymbol{\eta}, \boldsymbol{\sigma}$ and $\boldsymbol{\alpha}$ denote the stress tensor considering the back stresses, the Cauchy stress tensor and the back stress tensor, respectively. The subscript $m$ represents six components $(x x, y y, z z, x y, x z, y z)$ of the stress tensor. The subscript $n$ represents four directions of the metal sheet, where 0 represents the rolling direction, 45 represents the diagonal direction of the rolling and transverse directions, 90 represents the transverse direction, and ND represents the thickness direction. $g(\boldsymbol{\eta})$ is the plastic potential function. $\eta_{n}\left(\bar{\varepsilon}^{p}\right)$ is the flow stress in the $n$ direction considering the back stresses. $\bar{\varepsilon}^{p}$ is the equivalent plastic strain. $C_{1, m}$, $C_{2, m}$ and $\gamma_{m}$ can be calculated using Eqs. (7-9). $\eta_{n}^{0}, Q_{n}$, $b_{n}, C_{1, n}, C_{2, n}$ and $\gamma_{n}$ are the parameters of the work hardening rule and can be identified from the cyclic stress-strain curve in the $n$ direction. Compared with the parameters of the back stresses in the mixed hardening rule of the constitutive model before modification $\left(C_{1}, C_{2}\right.$ and $\gamma_{1}$ in Eq. (A5)), which are only identified from the cyclic stress-strain curve in the rolling direction, the parameters of the back stresses in the mixed hardening rule after modification $\left(C_{1, m}, C_{2, m}\right.$ and $\gamma_{m}$ in Eqs. (4-5)) are independent in different directions, and are identified from the cyclic stress-strain curves in four directions; thus, the anisotropic hardening under cyclic loading can be captured.

\section{Yield criterion:}

$$
\begin{gathered}
f(\boldsymbol{\eta})=\sqrt{F\left(\bar{\varepsilon}^{p}\right)\left(\eta_{y y}-\eta_{z z}\right)^{2}+G\left(\bar{\varepsilon}^{p}\right)\left(\eta_{z z}-\eta_{x x}\right)^{2}+H\left(\bar{\varepsilon}^{p}\right)\left(\eta_{x x}-\eta_{y y}\right)^{2}+2 L\left(\bar{\varepsilon}^{p}\right) \eta_{y z}^{2}+2 M\left(\bar{\varepsilon}^{p}\right) \eta_{z x}^{2}+2 N\left(\bar{\varepsilon}^{p}\right) \eta_{x y}^{2}} \\
2 F\left(\bar{\varepsilon}^{p}\right)=\frac{\eta_{0}^{2}\left(\bar{\varepsilon}^{p}\right)}{\eta_{90}^{2}\left(\bar{\varepsilon}^{p}\right)}+\frac{\eta_{0}^{2}\left(\bar{\varepsilon}^{p}\right)}{\eta_{N D}^{2}\left(\bar{\varepsilon}^{p}\right)}-\frac{\eta_{0}^{2}\left(\bar{\varepsilon}^{p}\right)}{\eta_{0}^{2}\left(\bar{\varepsilon}^{p}\right)} \\
2 G\left(\bar{\varepsilon}^{p}\right)=\frac{\eta_{0}^{2}\left(\bar{\varepsilon}^{p}\right)}{\eta_{N D}^{2}\left(\bar{\varepsilon}^{p}\right)}+\frac{\eta_{0}^{2}\left(\bar{\varepsilon}^{p}\right)}{\eta_{0}^{2}\left(\bar{\varepsilon}^{p}\right)}-\frac{\eta_{0}^{2}\left(\bar{\varepsilon}^{p}\right)}{\eta_{90}^{2}\left(\bar{\varepsilon}^{p}\right)} \\
2 H\left(\bar{\varepsilon}^{p}\right)=\frac{\eta_{0}^{2}\left(\bar{\varepsilon}^{p}\right)}{\eta_{0}^{2}\left(\bar{\varepsilon}^{p}\right)}+\frac{\eta_{0}^{2}\left(\bar{\varepsilon}^{p}\right)}{\eta_{90}^{2}\left(\bar{\varepsilon}^{p}\right)}-\frac{\eta_{0}^{2}\left(\bar{\varepsilon}^{p}\right)}{\eta_{N D}^{2}\left(\bar{\varepsilon}^{p}\right)} \\
2 L\left(\bar{\varepsilon}^{p}\right)=2 M\left(\bar{\varepsilon}^{p}\right)=2 N\left(\bar{\varepsilon}^{p}\right)=\frac{4 \eta_{0}^{2}\left(\bar{\varepsilon}^{p}\right)}{\eta_{45}^{2}\left(\bar{\varepsilon}^{p}\right)}-\frac{\eta_{0}^{2}\left(\bar{\varepsilon}^{p}\right)}{\eta_{N D}^{2}\left(\bar{\varepsilon}^{p}\right)}
\end{gathered}
$$

Here, $F\left(\bar{\varepsilon}^{p}\right), G\left(\bar{\varepsilon}^{p}\right), H\left(\bar{\varepsilon}^{p}\right), L\left(\bar{\varepsilon}^{p}\right), M\left(\bar{\varepsilon}^{p}\right)$, and $N\left(\bar{\varepsilon}^{p}\right)$ are the anisotropic parameters of the yield function and can be calculated from flow stresses considering back stresses in the rolling, diagonal, transverse and thickness directions (Eqs. (11-14)). Compared with the anisotropic parameters in the yield function of the constitutive model before modification
(Eq. (A6)), which are all identified from the directional initial yield stresses, all the anisotropic parameters of the yield function in the constitutive model after modification are identified from the directional flow stresses and become evolutionary during the working hardening. In this case, both the initial yield stress anisotropy and the subsequent anisotropic hardening can be captured.

\section{Flow rule:}

$$
\begin{aligned}
& d \boldsymbol{\varepsilon}^{p}=\frac{\partial g(\eta)}{\partial \boldsymbol{\eta}} d \lambda \\
& g(\boldsymbol{\eta})=\sqrt{F^{*}\left(\eta_{y y}-\eta_{z z}\right)^{2}+G^{*}\left(\eta_{z z}-\eta_{x x}\right)^{2}+H^{*}\left(\eta_{x x}-\eta_{y y}\right)^{2}+2 L^{*} \eta_{y z}^{2}+2 M^{*} \eta_{z x}^{2}+2 N^{*} \eta_{x y}^{2}} \\
& F^{*}=\frac{r_{0}}{r_{90}\left(1+r_{0}\right)} \\
& G^{*}=\frac{1}{1+r_{0}} \\
& H^{*}=\frac{r_{0}}{1+r_{0}}
\end{aligned}
$$




$$
L^{*}=M^{*}=N^{*}=\frac{\left(r_{0+} r_{90}\right)\left(1+2 r_{45}\right)}{2 r_{90}\left(1+r_{0}\right)}
$$

Here, $\varepsilon^{p}$ is the plastic strain tensor. $d \lambda$ is the plastic multiplier. $F^{*}, G^{*}, H^{*}, L^{*}, M^{*}$ and $N^{*}$ are the parameters of the plastic potential function and can be calculated from $\mathrm{R}$-values in the rolling, diagonal and transverse directions (Eqs. (17-20)). Note that it is possible to modify this plastic potential function with variable anisotropic parameters to capture the changes in R-values during forming when necessary. In this study, the changes in $\mathrm{R}$-values are not considered.

For the work hardening rule of the modified constitutive model (Eqs. (1-9)), the mixed hardening rule consisting of the isotropic and kinematic hardening rules was modified considering the cyclic anisotropic hardening behaviors in the rolling, diagonal, transverse and thickness directions. For the yield criterion, the Hill48 yield function was modified with the variable anisotropic parameters shown in Eqs. (10-14) to capture the anisotropic hardening behaviors in the rolling, diagonal, transverse and thickness directions. For the flow rule shown in Eqs. (15-20), the classical Hill48 plastic potential function with constant anisotropic parameters was adopted. For the constitutive parameter identification, flow stresses in the rolling, diagonal, transverse and thickness directions are required to determine the anisotropic parameters of the yield criterion and the parameters of the work hardening rule. The $\mathrm{R}$-values in the rolling, diagonal and transverse directions are required to calculate the anisotropic parameters of plastic potential functions.

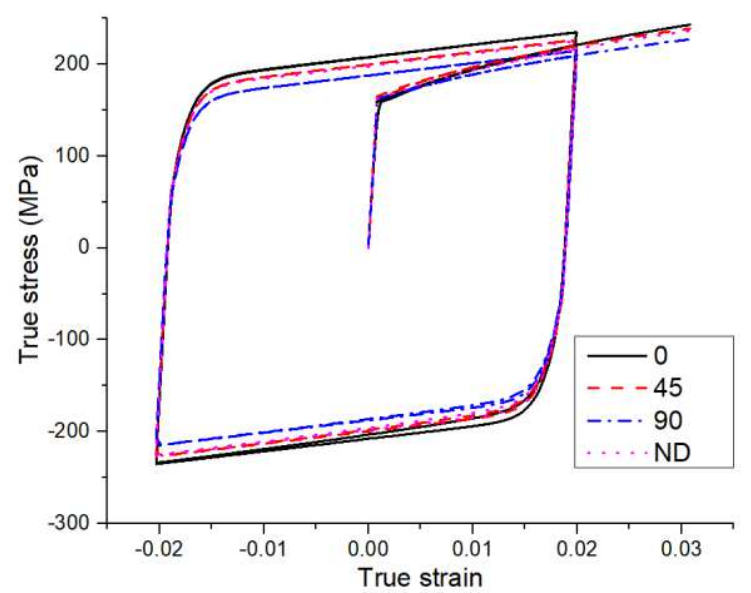

Figure 7 Stress-strain responses in different directions of SPCC under monotonic and cyclic loading conditions obtained by FE analysis.

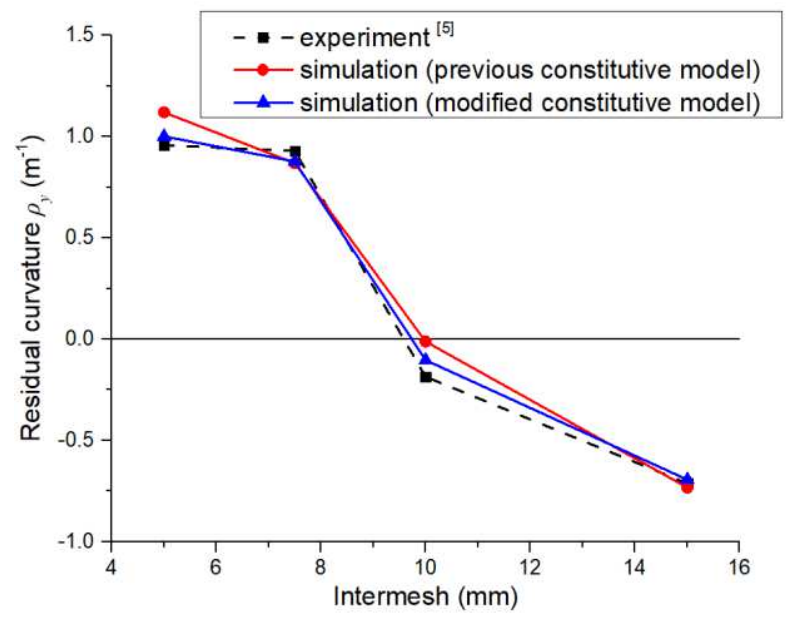

Figure 8 Experimental and simulation results of tension leveling.

The modified constitutive model considering the anisotropic hardening was implemented in Abaqus/Standard via user subroutine UMAT with the fully implicit backward Euler return mapping algorithm, and the successful application of the algorithm for anisotropic hardening was also reported in Ref.[18]. The FE analysis of tension leveling was conducted using the FE model mentioned in section 2 with the modified constitutive model. The material of the leveled strip is SPCC and the identified constitutive parameters for SPCC are shown in Table 4. The parameters of flow stresses and the plastic potential function are identified from experimental data in Refs. [5] and [17], and the flow stress in the thickness direction is calculated as the average of the flow stresses in the rolling, diagonal and transverse directions. The tensile and cyclic loading results in the rolling, diagonal, transverse and thickness directions obtained from the modified constitutive model for SPCC are shown in Figure 7, indicating the capability of the modified model to capture the anisotropic hardening behaviors of SPCC under monotonic and cyclic loading conditions. After conducting the FE analysis of tension leveling using the modified constitutive model, the residual curvatures in the $x$ direction were measured and compared with the simulation results obtained using the constitutive model in our previous study [4] (details in Appendix I, referred to as previous constitutive model) and the experimental results [5]. The comparisons are shown in Figure 8, indicating that the modified constitutive model can provide more accurate FE analysis results of tension leveling than the previous constitutive 
model because of the consideration of anisotropic hardening. The modified constitutive model can also be applied to simulate sheet metal forming processes involving plastic anisotropy under cyclic loading (an example of applying the modified constitutive model to the accurate simulation of a two-step drawing process is shown in Appendix II). The FE analysis of sheet metal forming processes considering the forming history (e.g., the forming strain history and residual stresses from the previous forming process) has a higher accuracy than that without considering the forming history [19]. Thus, the modified constitutive model can also contribute to the improvement of the accuracy of the FE analysis of sheet metal forming processes via a continuous simulation from leveling to forming.

Table 4 Constitutive parameters of modified constitutive model for SPCC

\begin{tabular}{|c|c|c|c|c|c|c|c|}
\hline \multirow{5}{*}{ Flow stresses } & Directions & $\eta^{0}$ & $Q$ & $b$ & $C_{1}$ & $C_{2}$ & $\gamma$ \\
\hline & 0 (rolling) & 158.9 & 50.4 & 65.4 & 54468.9 & 1359.7 & 889.3 \\
\hline & 45 (diagonal) & 165.1 & 36.0 & 83.9 & 54468.9 & 1359.7 & 889.3 \\
\hline & $\begin{array}{c}90 \\
\text { (transverse) }\end{array}$ & 162.0 & 27.0 & 83.0 & 54468.9 & 1359.7 & 889.3 \\
\hline & ND (thickness) & 160.9 & 32.6 & 82.9 & 54468.9 & 1359.7 & 889.3 \\
\hline \multirow{2}{*}{ Plastic potential function } & $\mathrm{H}^{*}$ & & $\mathrm{~F}^{*}$ & & $\mathrm{G}^{*}$ & \multicolumn{2}{|c|}{$\mathrm{L}^{*}, \mathrm{M}^{*}, \mathrm{~N}^{*}$} \\
\hline & 0.6688 & & 0.2562 & & 0.3312 & \multicolumn{2}{|c|}{1.4568} \\
\hline
\end{tabular}

\section{Conclusions}

The FE analysis of tension leveling was conducted using an established FE model in Abaqus/Standard with a static implicit analysis step, and the user subroutine UMAT was adopted to implement constitutive models to the FE analysis of tension leveling with the fully implicit backward Euler return mapping algorithm [4]. The effects of the yield point on the FE analysis results of tension leveling were confirmed by $\mathrm{FE}$ analysis using constitutive models with and without a yield point. The effects of plastic anisotropy on the curl and gutter of the leveled strips after tension leveling were also confirmed by the $\mathrm{FE}$ analysis of tension leveling with different anisotropic parameters of the Hill48 yield function. Since the anisotropic parameters can affect the results of the FE analysis of both curl and gutter after tension leveling, the constitutive model in our previous investigation [4] was modified using variable anisotropic parameters of the Hill48 yield function and different parameters for different directions of the mixed hardening rule to capture the anisotropic hardening behavior of materials under monotonic and cyclic loading conditions. The modified constitutive model was applied to the FE analysis of tension leveling, and more accurate simulation results were obtained. The modified model can also contribute to the improvement of the accuracy of the FE analysis of sheet metal forming via a continuous simulation from leveling to forming. The constitutive modeling method and its FE implementation demonstrated in this study can be adopted as an effective tool to investigate the effects of material properties on metal forming processes.

\section{Declaration}

\section{Acknowledgements}

The authors sincerely thanks to Professor Jun Yanagimoto of The University of Tokyo for his critical discussion and reading during manuscript preparation.

\section{Funding}

Supported by financial support from Guangdong Basic and Applied Basic Research Foundation (No. 2019A1515011282), Fundamental Research Funds for the Central Universities (21619336).

\section{Availability of data and materials}

The datasets supporting the conclusions of this article are included within the article.

\section{Authors' contributions}

Honghao Wang: Conceptualization, Methodology, Software, Investigation, Writing-original draft, Writing-review \& editing.

Ye Zhang: Software, Writing-review \& editing. Changxiang Fan: Methodology-advising, Writing-review \& 
editing.

Dexin Chen: Methodology-advising, Writing-review \& editing.

Jing Guo: Methodology-advising, Writing-review \& editing.

Jun Yanagimoto: Supervision, Writing - review \& editing.

\section{Competing interests}

The authors declare no competing financial interests.

\section{Consent for publication}

Not applicable

\section{Ethics approval and consent to participate}

Not applicable

\section{References}

[1] P. Zhao, C. Zhdou, W. Li, Q. Huang, Y. Shuang, Analysis of the strip curvature in tension levelling with FEM, Adv. Mater. Res. 572 (2012) 308-311. https://doi.org/10.4028/www.scientific.net/AMR.572.308.

[2] J. Zhang, C.L. Zhou, H.B. Li, X.C. Zhang, M. Li, Influence of Tension Leveling Parameters on the Microstructure and Mechanical Properties of Steel Strip, Jom. 69 (2017) 937-941. https://doi.org/10.1007/s11837-017-2272-3.

[3] A. Garcia, J. Trinidad, N. Otegi, J. Mendiguren, E.S. de Argandoña, E. Silvestre, L. Galdos, The influence of the kinematic hardening on the FEM simulation of tension levelling process, Procedia Manuf. 47 (2020) 1381-1386. https://doi.org/10.1016/j.promfg.2020.04.271.

[4] H. Wang, B. Wu, J. Yanagimoto, Elastic-Plastic Finite Element Analysis of Tension Leveling with Non-Associated Flow Rule and Mixed Hardening, Steel Res. Int. 90 (2019) 1-9. https://doi.org/10.1002/srin.201800401.

[5] F. Yoshida, M. Urabe, Computer-aided process design for the tension levelling of metallic strips, J. Mater. Process. Technol. 89-90 (1999) 218-223.

https://doi.org/10.1016/S0924-0136(99)00034-5.

[6] R. Schwab, V. Ruff, On the nature of the yield point phenomenon, Acta Mater. 61 (2013) 1798-1808. https://doi.org/10.1016/j.actamat.2012.12.003.

[7] R. Mahmudi, Yield point phenomenon in ultrafine-grained aluminium sheets, Mater. Lett. 19 (1994) 243-246. https://doi.org/10.1016/0167-577X(94)90164-3.

[8] Y. Zong, B. Shao, Y. Tian, D. Shan, A study of the sharp yield point of a Ti-22Al-25Nb alloy, J. Alloys Compd. 701 (2017) 727-731. https://doi.org/10.1016/j.jallcom.2017.01.110.

[9] A. Žerovnik, V. Pepel, I. Prebil, R. Kunc, The yield-point phenomenon and cyclic plasticity of the uniaxially loaded specimens, Mater. Des. 92 (2016) 971-977. https://doi.org/10.1016/j.matdes.2015.12.111.

[10] A. Žerovnik, R. Kunc, I. Prebil, Yield-point phenomenon in constitutive models of cyclic plasticity, Comput. Mater. Sci. 49 (2010) 473-482. https://doi.org/10.1016/j.commatsci.2010.05.038.

[11] J. Kim, K.C. Park, D.N. Kim, Investigating the fluting defect in $\mathrm{v}$-bending due to the yield-point phenomenon and its reduction via roller-leveling process, J. Mater. Process. Technol. 270 (2019) 59-81.

https://doi.org/10.1016/j.jmatprotec.2019.02.016.

[12] H. Wang, M. Men, Y. Yan, M. Wan, Q. Li, Prediction of Eight Earings in Deep Drawing of 57540 Aluminum Alloy Sheet, Chin. J. Mech. Eng. (2019) 32:76. https://doi.org/10.1186/s10033-019-0390-2

[13] B. Wu, H. Wang, T. Taylor, J. Yanagimoto, A non-associated constitutive model considering anisotropic hardening for orthotropic anisotropic materials in sheet metal forming, Int. J. Mech. Sci. 169 (2020) 105320. https://doi.org/10.1016/j.ijmecsci.2019.105320.

[14] J.J. Kim, Q.T. Pham, Y.S. Kim, Thinning prediction of hole-expansion test for DP980 sheet based on a non-associated flow rule, Int. J. Mech. Sci. 191 (2021) 106067.

https://doi.org/10.1016/j.ijmecsci.2020.106067.

[15] Q. Hu, J.W. Yoon, N. Manopulo, P. Hora, A coupled yield criterion for anisotropic hardening with analytical description under associated flow rule: Modeling and validation, Int. J. Plast. 136 (2021). https://doi.org/10.1016/j.ijplas.2020.102882.

[16] H. Wang, B. Wu, T. Higuchi, J. Yanagimoto, Tension leveling using finite element analysis with different constitutive relations, ISIJ Int. 60 (2020) 1273-1283. https://doi.org/10.2355/isijinternational.ISIJINT-2019-620.

[17] J. Huh, H. Huh, C.S. Lee, Effect of strain rate on plastic anisotropy of advanced high strength steel sheets, Int. J. Plast. 44 (2013) 23-46. https://doi.org/10.1016/j.ijplas.2012.11.012.

[18] B. Wu, H. Wang, A. Yoshimura, T. Taylor, N. Liu, Mechanics of Materials Analysis of rectangular cup drawing considering anisotropic hardening and cyclic effect for orthogonal anisotropic materials, Mech. Mater. 158 (2021) 103874. https://doi.org/10.1016/j.mechmat.2021.103874.

[19] A. Abvabi, B. Rolfe, P.D. Hodgson, M. Weiss, The influence of residual stress on a roll forming process, Int. J. Mech. Sci. 101-102 (2015) 124-136. https://doi.org/10.1016/j.ijmecsci.2015.08.004.

[20] J.E. Carsley, C. Xia, L. Yang, T.B. Stoughton, S. Xu, S.E. Hartfield-Wünsch, J. Li, Z. Chen, Benchmark 2 - Springback of a draw / re-draw panel: Part A: Benchmark description, 177 (2014) $177-182$. https://doi.org/10.1063/1.4849980.

[21] T.B. Stoughton, M.F. Shi, G. Huang, J.W. Yoon, Material characterizations for Benchmark 1 and Benchmark 2, 14 (2014) 9-14. https://doi.org/10.1063/1.4849976.

[22] J.E. Carsley, X. Chen, Z. Pang, Y. Liu, Benchmark 2 - Springback of a draw / re-draw panel: Part B: Physical tryout report, 188 (2014) $183-188$. https://doi.org/10.1063/1.4849981.

\section{Biographical notes}

Honghao Wang, born in 1993, is currently a $\mathrm{PhD}$ candidate at the University of Tokyo, Japan. He received his master degree from Graduate School of Engineering at the University of Tokyo, Japan, in 2018. His research interest includes the physical and numerical simulation of sheet metal forming.

E-mail: honghao.wang@cem.t.u-tokyo.ac.jp 
Ye Zhang, born in 1993 , is currently a $\mathrm{PhD}$ candidate at the University of Tokyo, Japan. He received his master degree from Graduate School of Engineering at the University of Tokyo, Japan, in 2018. His research interest includes the finite element analysis and composite materials.

E-mail: zhang-ye@cfrtp.t.u-tokyo.ac.jp

Changxiang Fan, born in 1990, is currently a project researcher of Research into Artifacts, Center for Engineering (RACE), School of Engineering, the University of Tokyo, Japan. He received Ph.D. degree in Precision Engineering in 2020 from The University of Tokyo, Tokyo, Japan. His research interests include mechanical design and robotics.

Tel: +86-13416158651; E-mail: fan@ race.t.u-tokyo.ac.jp

Dexin Chen, born in 1991, is currently associate professor at Institute of Advanced Wear \& Corrosion Resistant and Functional Materials, Jinan University, China. He received his $\mathrm{PhD}$ degree from South China University of Technology, China, in 2018. His research interests include surface modification and functional coatings.

Email: dxchen@jnu.edu.cn

Jing Guo is currently an associate professor affiliated with Guangdong University of Technology, China. He received his $\mathrm{Ph} . \mathrm{D}$. degree from LIRMM, CNRS-University of Montpelier,
France in 2016. His current research interests include robotic control and learning, haptic bilateral teleoperation, and surgical robotics. He has served as guest editor for IEEE RA-L, Frontiers in Robotics \&AI, etc.

E-mail: jing.guo@gdut.edu.cn

Jun Yanagimoto, born in 1961, is currently a professor at the University of Tokyo, Japan. He received his Ph.D. degree from Graduate School of Engineering at the University of Tokyo, Japan, in 1989. His research interest includes fundamental investigation in manufacturing formable high-strength steel strips with bimodal microstructure, physical and numerical simulations on metal, and decoding material genome for the analysis of microstructure evolution in hot forming.

E-mail: jun.52074.yanagimoto@cem.t.u-tokyo.ac.jp

\section{Appendix I. Hill48 yield criterion with non-associated flow rule and mixed hardening rule}

The Hill48 yield criterion (Eq. (A1)) with the non-associated flow rule (Eqs. (A2-A3)) and the mixed hardening rule (Eqs. (A4-A5)) of the constitutive model applied in our previous investigation are briefly summarized as follows:

$$
\begin{gathered}
f(\boldsymbol{\eta})=\sqrt{\frac{3}{2} \times \frac{F\left(\eta_{y y}-\eta_{z z}\right)^{2}+G\left(\eta_{z z}-\eta_{x x}\right)^{2}+H\left(\eta_{x x}-\eta_{y y}\right)^{2}+2 L \eta_{y z}^{2}+2 M \eta_{z x}^{2}+2 N \eta_{x y}^{2}}{F+G+H}}=\sigma^{Y} \\
d \boldsymbol{\varepsilon}^{p}=\frac{\partial g(\eta)}{\partial \eta} d \lambda \\
g(\boldsymbol{\eta})=\sqrt{\frac{3}{2} \times \frac{F^{*}\left(\eta_{y y}-\eta_{z z}\right)^{2}+G^{*}\left(\eta_{z z}-\eta_{x x}\right)^{2}+H^{*}\left(\eta_{x x}-\eta_{y y}\right)^{2}+2 L^{*} \eta_{y z}^{2}+2 M^{*} \eta_{z x}^{2}+2 N^{*} \eta_{x y}^{2}}{F^{*}+G^{*}+H^{*}}} \\
\sigma^{Y}=\sigma^{0}+Q\left(1-e^{-b \bar{\varepsilon}}\right)-\frac{C_{1}}{\gamma_{1}}\left(1-e^{-\gamma_{1} \bar{\varepsilon}^{p}}\right) \\
\boldsymbol{\alpha}=\boldsymbol{\alpha}_{1}+\boldsymbol{\alpha}_{2} \\
d \boldsymbol{\alpha}_{1}=\left(\frac{\eta C_{1}}{g(\eta)}-\gamma_{1} \boldsymbol{\alpha}_{1}\right) d \bar{\varepsilon}^{p} \\
d \boldsymbol{\alpha}_{2}=\frac{\eta C_{2}}{g(\eta)} d \bar{\varepsilon}^{p}
\end{gathered}
$$

where $f(\boldsymbol{\eta})$ and $g(\boldsymbol{\eta})$ are the yield function and plastic potential function, respectively. $(F, G, H, L, M, N)$ and $\left(F^{*}\right.$, $\left.G^{*}, H^{*}, L^{*}, M^{*}, N^{*}\right)$ are the anisotropic parameters of the yield function and plastic potential function, respectively. $\eta$ represents the stress tensor considering the back stresses, where $\boldsymbol{\eta}=\boldsymbol{\sigma}-\boldsymbol{\alpha}$, and $\boldsymbol{\sigma}$ and $\boldsymbol{\alpha}$ denote the Cauchy stress tensor and back stress tensor, respectively. $\varepsilon^{p}, d \lambda, \bar{\varepsilon}^{p}$ and $\sigma^{Y}$ are the plastic strain tensor, plastic multiplier, equivalent plastic strain and yield stress in the rolling direction of the sheet metal, respectively. $\sigma^{0}, Q, b, C_{1}, \gamma_{1}$ and $C_{2}$ are the parameters of the mixed hardening rule, and can be identified from the cyclic stress-strain curve in the rolling direction of the sheet metal. The anisotropic parameters of the yield and plastic potential functions are identified as:

$$
2 F=\frac{1}{\sigma_{90}^{2}}+\frac{1}{\sigma_{N D}^{2}}-\frac{1}{\sigma_{0}^{2}}
$$




$$
\begin{aligned}
2 G & =\frac{1}{\sigma_{N D}^{2}}+\frac{1}{\sigma_{0}^{2}}-\frac{1}{\sigma_{90}^{2}} \\
2 H & =\frac{1}{\sigma_{0}^{2}}+\frac{1}{\sigma_{90}^{2}}-\frac{1}{\sigma_{N D}^{2}} \\
2 N & =\frac{4}{\sigma_{45}^{2}}-\frac{1}{\sigma_{N D}^{2}} \\
F^{*} & =\frac{r_{0}}{r_{90}\left(1+r_{0}\right)} \\
G^{*} & =\frac{1}{1+r_{0}} \\
H^{*} & =\frac{r_{0}}{1+r_{0}} \\
L^{*}=M^{*} & =N^{*}=\frac{\left(r_{0+} r_{90}\right)\left(1+2 r_{45}\right)}{2 r_{90}\left(1+r_{0}\right)}
\end{aligned}
$$

where $\sigma_{0}, \sigma_{45}, \sigma_{90}, \sigma_{N D}$ are the yield stresses in the rolling, diagonal, transverse and thickness directions of the sheet metal, respectively. $r_{0}, r_{45}, r_{90}$ are the Lankford values in the rolling, diagonal and transverse directions of the sheet metal, respectively.

\section{Appendix II. Application of modified constitutive model to FE analysis of two-step drawing process}

The schematic of the two-step drawing process for a DP600 steel sheet is shown in Figure A1, where the drawing direction is the $z$ direction and the lower surface of the undeformed sheet is the zero position of the $z$-axis. This process is part of Benchmark 2 of NUMISHEET 2014 to predict the sprung shape of a rectangular drawing cup after a two-step drawing process [20]. In the first drawing, the tooling radius $\mathrm{R}$ of the upper die and punch is $12 \mathrm{~mm}$ and the punch stroke is $32.4 \mathrm{~mm}$. In the second drawing, the tooling radius $\mathrm{R}$ of the upper die and punch is $8 \mathrm{~mm}$. The deformed DP600 steel sheet in the first drawing process is drawn again, and the punch stroke of the second drawing is $47.5 \mathrm{~mm}$. A blank holder force of $595 \mathrm{kN}$ is provided by the lower die in the two-step drawing process. Note that all dimensions of the lower die, upper die and punch are the same for the first and second drawing processes except for the tooling radius of the upper die and punch (tool dimensions shown in Figure A2). The dimensions of the DP600 steel sheet are $300 \mathrm{~mm}(x) \times 250 \mathrm{~mm}(y) \times 1.0 \mathrm{~mm}(z)$ with the rolling direction aligned along the $300 \mathrm{~mm}$ length [20]. After the two-step drawing process, the rectangular drawing cup is trimmed along the centerline of the $y$ direction, and the sprung shape of the trimming edge in the $x-z$ plane is measured. The FE model of the two-step drawing process was established on the basis of the tool and sheet dimensions, where the tools were modeled as rigid bodies and the DP600 steel sheet was discretized as the first-order brick element. The mesh size of the DP600 steel sheet was $2.5 \mathrm{~mm}(x) \times 2.5 \mathrm{~mm}(y)$ with three elements in the thickness direction. The friction coefficient between the tool and the sheet was set to 0.1 . The modified constitutive model mentioned in section 4.2 was applied to describe the material behaviors via UMAT during the FE analysis, and the constitutive parameters of DP600 identified from material data in Ref. [21] are shown in Table A1 (note that only the cyclic stress-strain curve in the rolling direction is available in Ref. [21]; thus, $C_{1}, C_{2}$ and $\gamma$ in the diagonal, transverse and thickness directions are assumed to be equal to the corresponding values in the rolling direction). The static implicit step was adopted to simulate the two-step drawing process, and the comparison of the sprung shapes of the simulation and the experiment [22] after the two-step drawing is shown in Figure A3, showing the capability of the modified constitutive model to simulate sheet metal forming accurately.

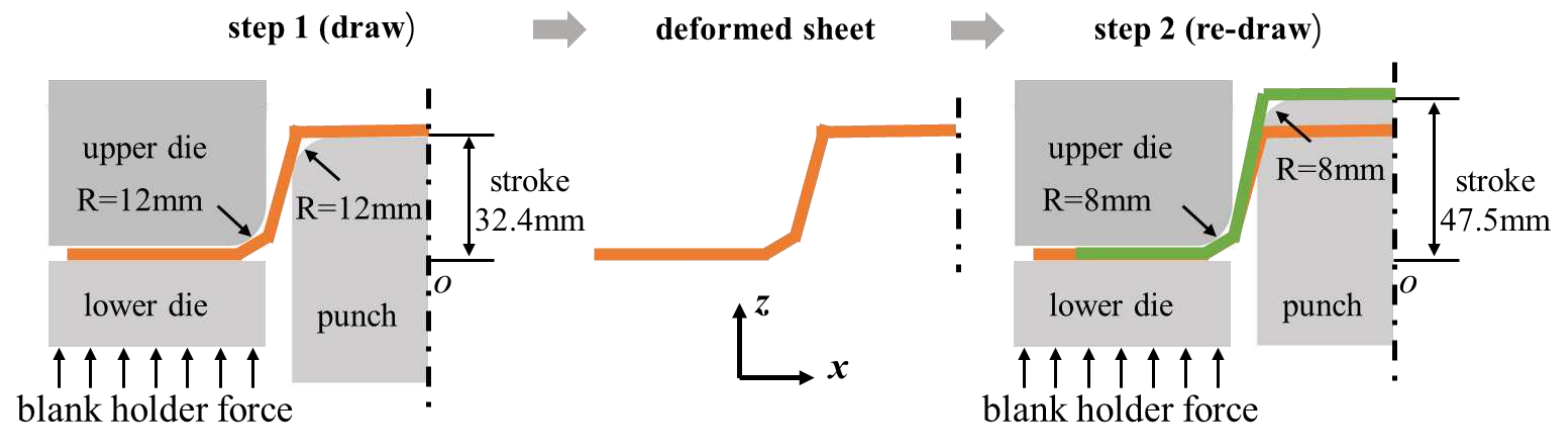

Figure A1 Schematic of two-step drawing process for DP600 steel sheet. 


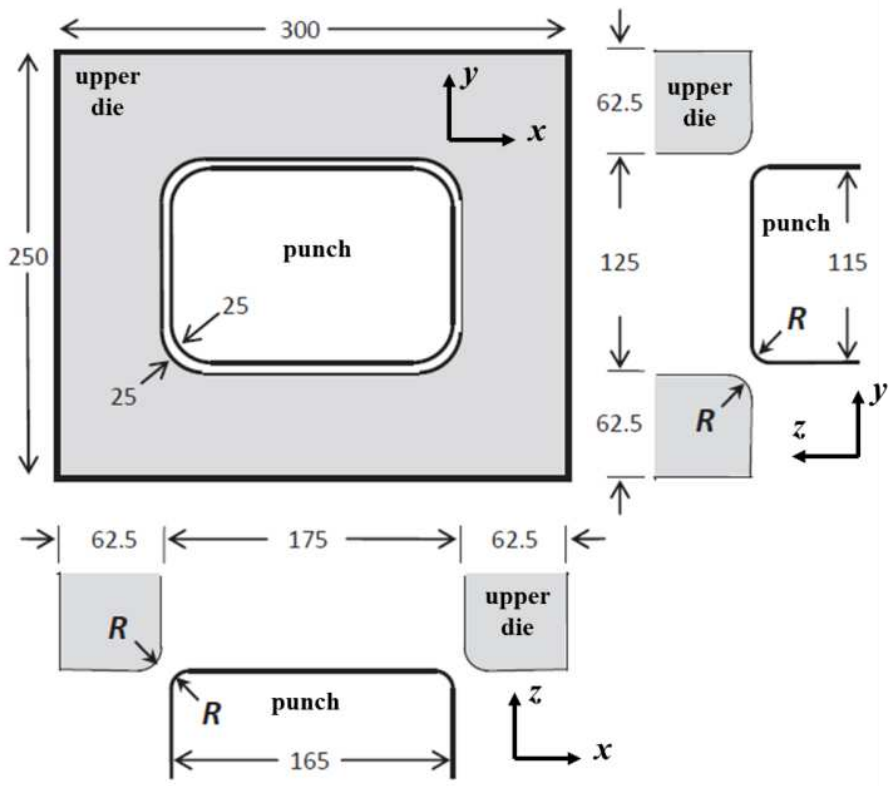

Figure A2 Dimensions of tools [20].

Table A1 Constitutive parameters of modified constitutive model for DP600

\begin{tabular}{|c|c|c|c|c|c|c|c|}
\hline \multirow{5}{*}{ Flow stresses } & Directions & $\eta^{0}$ & $Q$ & $b$ & $C_{1}$ & $C_{2}$ & $\gamma$ \\
\hline & 0 (rolling) & 408.1 & 241.7 & 21.9 & 32381.2 & 1049.1 & 180.3 \\
\hline & 45 (diagonal) & 405.6 & 184.1 & 41.5 & 32381.2 & 1049.1 & 180.3 \\
\hline & 90 (transverse) & 440.2 & 174.9 & 41.7 & 32381.2 & 1049.1 & 180.3 \\
\hline & ND (thickness) & 401.6 & 186.1 & 33.7 & 32381.2 & 1049.1 & 180.3 \\
\hline \multirow{2}{*}{ Plastic potential function } & $\mathrm{H}^{*}$ & & $\mathrm{~F}^{*}$ & & $\mathrm{G}^{*}$ & \multicolumn{2}{|c|}{$\mathrm{L}^{*}, \mathrm{M}^{*}, \mathrm{~N}^{*}$} \\
\hline & 0.485 & & 0.538 & & 0.515 & \multicolumn{2}{|c|}{2.040} \\
\hline
\end{tabular}




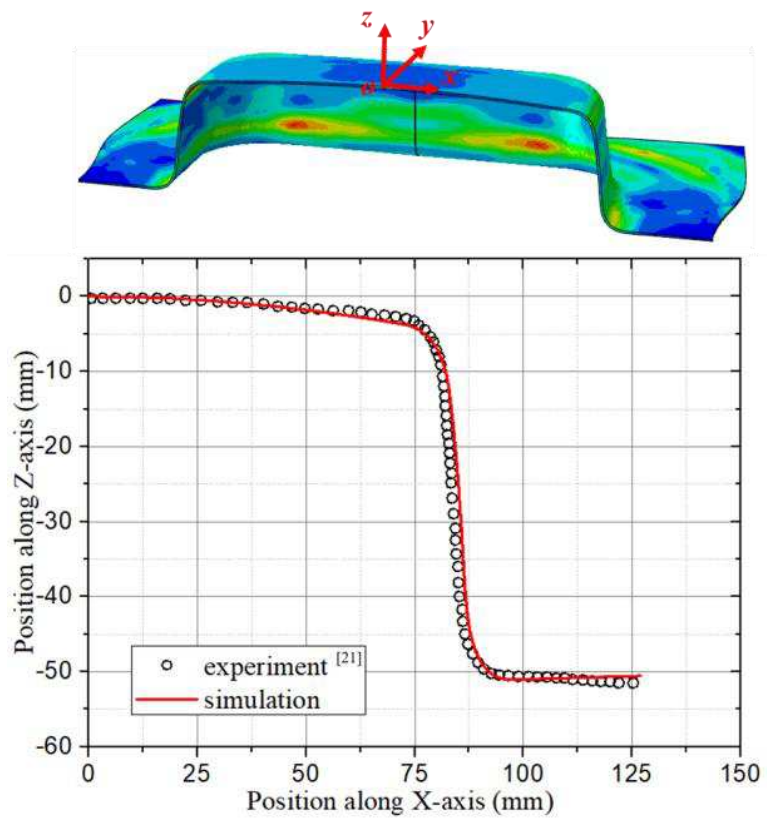

Figure A3 Experimental and simulation results of sprung shapes in $x$ - $z$ plane after two-step drawing. 